\title{
Alexander Anchía Vindas: EI Misterio en Ti Despertó
}

(Costa Rica: Editorial Grafiká, 2018, 58 págs.)

Juan Ángel Torres Rechy

$\mathbf{M}$ i amistad con Alexander Anchía se remonta a más de un lustro. Las gestiones poéticas y culturales de Alfredo Pérez Alencart, poeta y profesor de la Universidad de Salamanca, hicieron que nuestros caminos se encontraran en la ciudad de la Máxima Casa de Estudios ocho veces centenaria. La afición de Anchía Vindas por la literatura clásica cristiana se puso de relieve de inmediato en nuestras conversaciones, y me sentí animado a conocer su obra. En el transcurso de tiempo desde aquella reunión hasta el presente no hemos perdido el contacto, si bien en ocasiones ha habido paréntesis de silencio, que como no puede ser de otra forma, han permitido que cada uno por su propia ruta reme mar adentro en la experiencia estética del verso a lo divino.

La Dedicatoria de El Misterio en Ti Despertó ofrece gratitudes a las personas implicadas en el libro, entre quienes se encuentran escritores, artistas visuales y amigos, pero también brinda una clave de lectura, relacionada con el depositario principal de la ofrenda poética, Dios: «[...] mi objetivo no es la gloria, ni el aplauso, eso es sólo para Dios, y él quiere que la gente le hable y que tenga encuentros íntimos con ÉL, quizá sea muy ambicioso, pero esa es la propuesta.»
El volumen cuenta con dos secciones biográfico-curriculares. La primera se encuentra al inicio de la obra, con información sobre Anchía Vindas. La segunda cierra el poemario, con noticias de los artistas visuales. El prólogo lo firma Alfredo Pérez Alencart. Los títulos de las composiciones a veces resultan transparentes: «Oficio del místico», «La casa de Dios», «Nochebuena», «Misterio gozoso», «Consejos breves de San Juan de la Cruz a un aprendiz de místico», «El espíritu de Sibö», «Tagore, maestro de la esencia», etc. En otros casos, reservan el sentido de las composiciones: «Encrucijada», «¿Debo escoger?», «La suerte no conocida de los números», «Claridad», etc. Cuatro piezas son prosa poética y 26 verso libre.

Pérez Alencart esboza un panorama nítido del papel de Anchía Vindas en la poesía religiosa. Recupera para el lector versos de «Encrucijada» y los presenta bajo la perspectiva del tono de voz del vate de Costa Rica. «En Anchía - dice el poeta y profesor de la Universidad de Salamanca- lo místico no está disfrazado con aura o sudario que inclinen al bostezo: lo suyo es palabra fresca emparrada a la bravura de Creer.» El misticismo destaca. Constituye un dispositivo inmaterial cuyos efectos repercuten tanto en el sujeto 
lírico como en sus prójimos: «Su doctrina no es convencer; es permitir que se convenzan. [...] Su paga no la dicta el aplauso, o la palmadita en la espalda», dice en «Oficio del místico». En última instancia, como la Ítaca para el poeta antiguo, para Alexander Anchía el amor se erige en puerto: «Volvemos al amor $\mid$ y con el amor $\mid$ deshojamos | el camino de la muerte» («Asombro sobre el Cantar»), «Noche perfumada | de virgen sensualidad, | espectáculo | para este viaje interminable» («Noche mística»).

La lectura - y creación - del mundo del autor de Puentes inconexos parte de narraciones diversas. En primer término, se encuentra la Biblia. El cristianismo dicta pautas de educación sentimental, encaminada tanto a la experiencia plena de la vida de los sentidos, como a la de otra vida distinta, no visible, recogida en el seno de la divinidad. En «Nochebuena», leemos: «¡Tu Noche!, | porque presta alas a los niños, | para que sepan de un cielo | donde el camino no acaba.» En «La casa de Dios», apreciamos cómo el recinto sagrado se ubica tanto en un plano trascendente como en uno más cercano a nosotros: "Cualquier espacio | donde irrumpa luz, | tras cielo o la sonrisa | de un niño. || Ni tan grande | para no recorrerla | en una vida, || ni tan pequeña | para que un colibrí | no construya altar | alrededor de ella.»

Por igual, el esqueleto que sostiene el entramado semántico del vate está hecho, si bien en menor medida, del pensamiento mítico de pueblos indígenas costarricenses. En «El espíritu de Sibö», Anchía Vindas ofrece un programa de lectura de la selva - y con ella del mundo- donde cada uno de los seres vivos constituye una manifestación directa del Dios Sibö, cuya voluntad originaria y última no era otra sino atraer a sí la mirada y el amor de sus criaturas racionales. «En el principio | Sibö | hizo la selva | para propagar sus leyendas. || Se dividió en | hormigas, pájaros, | cocobolos | que administrasen su | conocimiento.»»

En otro orden de cosas, una galería de ocho ilustraciones conduce al lector por distintos escenarios que constituyen elementos estéticos tanto autónomos como complementarios de la voz lírica. Los dibujos tienen firmas de amigos del poeta. Los cuadros sugieren las ideas de peregrinaje, encuentro con la ciudad, inocencia, fe, comunión, madurez, tristeza, etc. La portada del tomo, con fotografía de Henry Rojas, entabla un acertado diálogo con el título.

Si tuviéramos que confrontar el poemario de Anchía Vindas con publicaciones de otros poetas contemporáneos, podríamos resaltar coincidencias con el autor del prólogo, Pérez Alencart, en relación con el reflejo de una vivencia personal de Dios tocada por características únicas, tal como se aprecia en Cristo del alma. En su Dedicatoria, Anchía lo menciona, mediante cita de R. W. Emerson: «Dios entra por una puerta privada en cada individuo.» Otra obra de cuya lírica asimismo se nutre la del autor de El Misterio en Ti Despertó es la del poeta salmantino Luis Frayle Delgado. Rasgos compartidos de la exploración de lo trascendente se ponen de manifiesto en libros como La luz que se filtra, donde escenarios cotidianos de la naturaleza sirven de reflejo de otra realidad no palpable. Así lo expresa Anchía Vindas: «Mensajero el viento | para mi pregunta abierta...»

Suzhou, China, 30 de septiembre de 2018 